\title{
SOBRE MÉTRICA COMPARADA
}

\author{
José Domínguez Caparrós
}

A la hora de definir y explicar un programa de actividades comparatistas en el campo de la métrica, es imprescindible mirar a lo que sobre el asunto dicen tanto quienes tratan de definir la literatura comparada como quienes tratan de definir la métrica. En segundo lugar, habrá que examinar qué es lo que hacen las investigaciones métricas que puede ser calificado de comparatista.

\section{TEORÍA DE LA LITERATURA COMPARADA Y MÉTRICA}

Aunque no es éste el momento de plantear una definición o discusión sobre qué es la literatura comparada, porque tampoco es el objetivo de este trabajo, sí es útil observar cómo no faltan las referencias a la métrica en las discusiones - nada escasas, por otra parte- acerca de la disciplina comparatista, entendida, como quiere Claudio Guillén (1985: 14), no sólo como una rama de los estudios literarios, sino como una tendencia, «o sea, una forma de exploración intelectual, un 
quehacer orientado por inquietudes e interrogaciones específicas». Por ser «rama de la investigación literaria que se ocupa del estudio sistemático de conjuntos supranacionales», aporta a la historia literaria, según el mismo Claudio Guillén, «unas clases y categorías que no son meramente nacionales». No falta, entre los ejemplos de estas categorías, la métrica, cuando sigue diciendo el crítico español: «Piénsese en un género multisecular como la comedia, un procedimiento inconfundible como la rima, un vasto movimiento, europeo y hasta mundial, como el Romanticismo» (Guillén, 1985: 13).

El comparatismo en métrica tiene que partir de una constatación como la que hace Wolfgang Kayser al principio de su presentación general - y comparada- de los conceptos fundamentales del verso:

Por más que nos remontemos en la historia de la literatura de nuestro pueblo o de otro extranjero, tropezamos siempre con una forma de lenguaje, extrañamente delimitada, que se designa tradicionalmente con el nombre de verso (Kayser, 1972: 103-104).

Si fuéramos antropólogos podríamos continuar la indagación de los fundamentos de esta constante expresiva del hombre y quizá llegáramos a confirmar una observación como la de Eleazar Meletinsky (1989: 16) que traduzco seguidamente:

La calidad estilística del arte verbal primitivo está unida al rito mágico en un tiempo en que la poesía depende del saber mítico y sagrado... Por eso la poesía ritual lírico-épica es cantada, después versificada, caracterizada por un estilo específico, mientras que la narración del mito en prosa, en el cuadro del rito o fuera de él, es neutra desde un punto de vista estilístico.

El origen sagrado y mítico de la poesía -Platón nos ilustraría también sobre estas relaciones- explica unas características de estilo entre las que se encuentran el canto y el verso ${ }^{1}$. Pero no vamos a seguir nuestra indagación por este terreno, sino que volvemos al más familiar al teórico de la literatura.

1 No es inoportuno recordar que Aristóteles fundamenta en la «naturalidad» de imitación, armonía y ritmo el nacimiento de la poesía: «Siéndonos, pues, natural el imitar, así como la armonía y el ritmo (pues es evidente que los metros son partes de los ritmos), desde el principio los mejor dotados para estas cosas, avanzando poco a poco, engendraron la poesía partiendo de las improvisaciones» (1448b). 
Aceptada la base común sobre la que establecer la comparación (el verso), las diferencias saltan inmediatamente a la vista en cuanto que observamos la influencia que los diferentes sistemas lingüísticos tienen en la morfología de sus respectivos versos. Ahora bien, estas diferencias no constituyen una barrera, sino un acicate estético para la vida artística del verso. No nos van a faltar ejemplos que demuestren cómo en la comparación, en la imitación de formas métricas extrañas encuentra la poesía una de sus más importantes fuentes de renovación. Los teóricos de la literatura comparada no se han olvidado del importante papel del intercambio de formas métricas. Así, en el contexto de una discusión sobre invariantes del lirismo, Etiemble trata de los metros y las formas bajo el epígrafe de «lo propio del lirismo», donde también caben las imágenes y los temas. Nos interesa ahora oír sus palabras:

\begin{abstract}
Ciertamente, la naturaleza de cada lengua orienta la factura de los poemas. [...] Una lengua que ha perdido el sentido de las sílabas largas y breves no construirá jamás versos basados en la cantidad de las sílabas y cantará de otra manera. Una lengua como el francés poco y regularmente acentuada, no organizará su prosodia sobre el acento tónico. Acentuado en la inicial, el húngaro tendrá otras dominantes métricas distintas seguramente a las del polaco, acentuado en la penúltima. Con tales precisiones, podemos admirar cómo cada lengua, en el interior de su sistema, o por acción de sistemas extranjeros, crece en estructuras líricas. Contaminados, uno por la métrica árabe, otro por la métrica india, la lírica persa y la malaya alcanzarán esquemas originales; de igual manera ocurrió con la poesía húngara después de su encuentro con Inglaterra y Francia (gracias a la revista $N y u g a t$ ) (Etiemble, 1974: 121-122).
\end{abstract}

En la lucha entre los límites que impone la lengua propia y el ejemplo de manifestaciones artísticas en otras lenguas (con límites distintos) se produce una renovación en el verso que no es distinta de la que se da en otros aspectos de la obra literaria y que hace necesario el trabajo del comparatista. Bien claro lo dice Claudio Guillén (1985: 22):

Es erróneo tener presente, como modelo o imagen del gran escritor, a quien encaja perfectamente en el homogéneo entorno cultural que lo rodea, ciñéndose a una sola lengua, un sistema literario único, unos procedimientos cerrados de versificación, un círculo social suficiente.

El comparatismo es necesario para entender la estética de un autor o una época. Y también para comprender la historia de una versifica- 
ción ${ }^{2}$. Consecuencia ineludible es que el estudio de una literatura no puede prescindir de la comparación, que además actuará como correctivo de las visiones demasiado centradas en las formas de una literatura nacional. Al tiempo que no es raro observar cómo «cuestiones de teoría poética y de los géneros no se pueden solucionar adecuadamente sobre la base de una única literatura nacional» (Schmeling, 1984: 10). Porque, según aclara René Wellek (1969: 62):

El gran argumento a favor del término «literatura comparada» o «general», o simplemente «literatura» sin más, es la falsedad evidente de la idea de una literatura nacional conclusa en sí misma. La literatura occidental, por lo menos, forma una unidad, un todo.

Eso sin insistir, desde el lado de los resultados de los análisis concretos, en las «[...] consecuencias grotescas cuando los problemas literarios se estudian con referencia a puntos de vista expresados en una determinada lengua y a textos y documentos escritos en dicha lengua solamente» (Wellek, 1969: 64).

Es oportuno también reproducir ahora lo que László Gáldi dice, al principio de la introducción a su Esquisse d'une histoire de la versification roumaine, sobre el carácter de su trabajo:

[...] intentaremos satisfacer en todos los aspectos a las exigencias de una disciplina que nos gustaría considerar como la «historia comparada de la versificación». Porque no es en absoluto dudoso que existe una historia - aún apenas entrevista - del verso europeo en tanto que parte integrante de la historia de la civilización europea; por consiguiente, la evolución del verso rumano no puede ser en absoluto examinada en sí misma. Los contactos múltiples que el pueblo rumano ha tenido con una serie de pueblos y de civilizaciones nacionales nos obligan a enfocar esta evolución bajo el signo del comparatismo (1964: 5).

Y, en efecto, el índice del libro ya es bastante elocuente, cuando habla de reformas de origen húngaro y reformas de origen polaco, por

2 Otra vez acudo a Wolfgang Kayser (1972: 130) para reproducir sus nítidas palabras: «Casi siempre los trabajos relacionados con problemas históricos del verso obligan a dirigir la mirada al extranjero, pues precisamente en este terreno, desde el principio, han sido grandes los intercambios e influjos recíprocos, puesto que en la métrica antigua del latín medieval existen fuentes comunes de influencia. La observación minuciosa de cómo se han ejercido estos influjos en pugna con el sentimiento autóctono del verso promete valiosas deducciones sobre las fuerzas que actúan en la literatura de cada país». 
ejemplo. Allí encontramos también términos españoles como: alejandrino, verso de arte mayor, romancero español, o seguidilla.

\section{MÉTRICA COMPARADA}

Si de las observaciones generales pasamos a fijarnos en el lugar de las cuestiones de métrica en un plan de estudios comparatistas, este lugar está entre el grupo de problemas de que se ocupa la POÉTICA COMPARADA. Disciplina que, según P. Brunel (1983: 135), trata de la comparación de las prácticas literarias, «de la escritura, en el sentido en el que se emplea normalmente este término hoy». Es decir, la métrica comparada se integra en el estudio de las formas. Un esquema de los apartados que constituyen el mencionado estudio de las cuestiones formales nos lo ofrece Jean-Louis Backès (1989), quien organiza su presentación de POÉTICA COMPARADA en: MÉTRICA GENERAL, RETÓRICA, TEORÍA DE LOS GÉNEROS ${ }^{3}$.

En el contexto de las discusiones generales, insistamos en el necesario carácter comparatista del estudio del verso. Acudimos otra vez a Claudio Guillén, quien en este punto se basa en el trabajo presentado por Craig LaDrière al Segundo Congreso de la Sociedad Internacional de Literatura Comparada sobre el método comparativo en el estudio de la prosodia, publicado en 1959. Del comentario de Claudio Guillén, reproducimos las siguientes palabras:

Pues bien, LaDrière razona con vigor que el examen prosódico de las estructuras del verso ha de ser por fuerza comparativo. Toda prosodia es una teoría. Pero si ésta se basa en el corpus de una sola literatura o tradición lingüística se corre el riesgo de que sea insuficiente. Tan sólo el inventario previo de los principales sistemas prosódicos da acceso con claridad a las relaciones de éstos con las lenguas o familias de lenguas. Por la ausencia de la rima el japonés se asemeja más al latín que al chino (Guillén, 1985: 195).

3 Antes de entrar en una mayor precisión de lo que se deba entender por MÉTRICA COMPARADA, recordemos la estrecha relación que $\mathbf{R}$. Jakobson establece entre poética comparada y tipología métrica. En palabras del teórico rumano Adrian Marino (1988: 124-125), que traduzco del francés: «Roman Jakobson plantea de entrada el problema mismo de la poética comparada a propósito de la tipología métrica. Esta desembocará en el "desarrollo gradual de la tipología métrica y quizá en el estudio comparado de las literaturas y de las culturas"». 
No vamos a seguir dando detalles de los parentescos prosódicos entre distintos sistemas de versificación. Parentescos que quedan perfectamente ilustrados en el párrafo de LaDrière que Claudio Guillén reproduce a continuación.

Ya antes René Wellek (1969: 63) había sostenido:

La historia de temas y formas, de artificios y géneros, es, evidentemente, internacional. [...] Incluso la historia de la métrica, aunque íntimamente vinculada a los diferentes sistemas lingüísticos, es internacional.

Por eso más adelante vuelve a mencionar la posibilidad del intento de una historia comparada de la métrica, que ilustra con el ejemplo de trabajos como el de Antoine Meillet (1923) sobre los orígenes indoeuropeos de los metros griegos, o el de R. Jakobson (1933) sobre el verso épico yugoslavo y su proximidad «de esta pauta clásica que combina un verso silábico con una cláusula cuantitativa de singular rigidez» (Wellek, 1969: 205).

Para terminar, insisto en la necesidad de una métrica comparada, preconizada desde las reflexiones sobre la comparatística. El siguiente párrafo, que puede leerse en una presentación general de la literatura comparada (Brunel, Pichois y Rousseau, 1983: 140), fundamenta muy bien el carácter comparatista de los estudios de métrica:

\begin{abstract}
¿Por qué no pensar también en una versificación comparada? En 1841, en su Ensayo filosófico sobre el principio y las formas de la versificación, Edelestand Du Méril declara que «antes de investigar bajo qué influencias literarias la imaginación de un pueblo se ha desarrollado, y qué acción ejerce a su vez sobre el desarrollo de las naciones extranjeras, se siente [...] la necesidad de examinar qué papel corresponde a la versificación en la historia comparada de las literaturas». Cuarteto, tercia rima, dístico, combinaciones tan extendidas; verso libre, verso blanco, rima, ritmo, vocabulario prosaico o poético, problemas de importancia general: todo esto sólo raramente ha sido examinado. Cómo la poesía está unida a ciertas técnicas, buen asunto para un comparatista medievalista. ¿Qué se entiende por poema en prosa según las literaturas? Al final, incluso las nociones de prosa y de poesía, comparativamente estudiadas, permitirían aclarar un poco la noción de literatura.
\end{abstract}

La conclusión que se impone parece ser que no sólo es posible una métrica comparada, sino que sólo es posible un estudio de la versificación que tenga muy presente la comparación entre distintos sistemas prosódicos. 
Veamos ahora, desde el campo de las teorías métricas, qué se dice sobre una métrica comparada.

\section{CONVENCIÓN Y COMPARACIÓN}

La aludida dependencia que el verso tiene respecto de un determinado sistema lingüístico no anula otro de los aspectos esenciales de los hechos métricos: el convencional.

Un lingüista que tanto ha hecho por la métrica comparada como Roman Jakobson insiste en el aspecto convencional de las leyes rítmicas, que las vincula a la poética. Por venir del sabio ruso, estas palabras tienen un valor especial:

El autoproclamado «espíritu de la lengua» (aplicado a la rítmica) se revela frecuentemente sometido a examen que no es más que una suma de costumbres rítmicas propias de tal individuo o de tal escuela poética.

Estas palabras están dichas a propósito de afirmaciones tan frecuentes en los tratados de métrica como las que asocian determinados fenómenos rítmicos al carácter de una lengua. Recordemos la «naturalidad» del octosílabo en la poesía española, o la posibilidad del triunfo de la rima asonante en una lengua con vocales tan claras como la castellana. Jakobson ponía como ejemplo afirmaciones corrientes de los manuales escolares rusos que sostienen cómo el sistema silábico se ve como extranjero, frente a la acomodación del sistema tónico al espíritu del ruso.

Es más. Frente a quienes piensan que el verso correcto será leído siempre como tal aunque se escriba todo seguido como la prosa, afirma Jakobson (1923: 40-41):

[...] que si el Monsieur Jourdain de Molière podía no sospechar que hablaba en prosa, debía a pesar de todo tomar necesariamente conciencia de los versos, percibirlos y experimentarlos en cuanto tales; por supuesto, puede no tener la menor sospecha de ninguna terminología prosódica, pero en la medida en que, en presencia de los versos, no los percibe como un fenómeno que pertenece a un sistema lingǘstico completamente diferente, los versos en tanto que versos (respectivamente sus elementos) sencillamente no existen para él. 
Este ingrediente es esencial para comprender la relación del verso con lo social, en sentido amplio, lo que da una dimensión mayor al comparatismo métrico, que no se limita a los rasgos prosódicos y estructurales, sino que implica muchos más aspectos. Aunque nos limitemos a la comparación de las propiedades formales de los distintos sistemas métricos, no sobra recordar la amplitud de campos en los que se puede apreciar una intervención de las características métricas. Por poner un ejemplo muy elocuente, véase la perspectiva, que traza John Lotz al final de su imprescindible presentación general de la métrica, desde el punto de vista de sus componentes lingüísticos. Allí se indica que la descripción métrica debería integrarse en un esquema más amplio de relaciones con fenómenos de otras disciplinas sociales. Debe contarse con el desarrollo histórico y con los análisis comparados de los mismos fenómenos métricos. En la evolución histórica no se pueden olvidar los cambios que tienen lugar debidos al gusto, es decir, «actitudes subjetivas hacia los sistemas métricos como expresiones de la experiencia poética y los cambios concomitantes en la forma métrica» (1974: 980). Pero el párrafo final es de lo más pertinente para nuestra argumentación en este momento. Dice Lotz (1974: 981):

\begin{abstract}
Además de sus aspectos lingüísticos el estudio de la métrica está conectado también con otros campos; por ejemplo, los estudios literarios (el metro empleado fundamentalmente como artificio poético), la antropología y la etnología (la existencia de poesía popular y «culta», el uso cultural de las formas métricas), la psicología y la estética (el efecto especial del metro comparado con el uso del lenguaje en la prosa literaria y el estilo coloquial), la sociología (la estratifícación de autores y sus públicos), y la historia cultural en general (el papel de la métrica y la poesía en el contexto completo de la totalidad de la cultura y los cambios que experimenta en el tiempo).
\end{abstract}

Hay aquí todo un programa amplio para el comparatismo de la métrica.

Aunque más adelante tengamos que volver al trabajo de Rowena Fowler sobre métrica comparada, conviene destacar ahora su observación sobre las consecuencias socioculturales que tiene el uso de una determinada forma métrica: un escritor negro de Senegal, por ejemplo, que emplea el verso alejandrino clásico francés, sin duda, compromete su sentido de la independencia:

La elección de un metro es «emblemática» (para usar el término de John Hollander) y puede verse como un gesto de solidaridad con la cultura de la 
que se adopta. Los poetas de un país africano que no tiene un sistema métrico nativo pueden elegir entre escribir en las formas europeas (inglés, francés o portugués), asimilar estas formas en su propia lengua, o eludir del todo el metro (1977: 298).

Ni que decir tiene que cada una de estas opciones adquiere un significado que fácilmente se teñirá de matices políticos.

\author{
Desde posiciones fundamentalmente idealistas, Emilio García \\ Gómez puede sostener que
}

\begin{abstract}
una métrica no es tan sólo una legislación fonética y rítmica, sino una expresión artística que nace del fondo "vital» de una cultura y de un lenguaje, y que se identifica con ellos, hasta el punto de convertirse, como tantos otros aspectos culturales, en algo «incomunicable» en su totalidad «radical» (1968: 280) ${ }^{4}$.
\end{abstract}

En su trabajo sobre «La place et le rôle de la métrique dans une théorie de la littérature» (1974), Jean-Louis Backès somete a crítica los presupuestos ideológicos que pueden descubrirse bajo las apariencias más científicamente objetivas de las afirmaciones de una preceptiva métrica tradicional ${ }^{5}$.

${ }^{4}$ El fondo vital de la cultura popular del sur de la península sería la base para las comparaciones que el mismo Emilio García Gómez lleva a cabo entre las formas métricas arabigoandaluzas y españolas, y cuya tesis podríamos resumir en palabras del mismo arabista como sigue: «Hay dos métricas clásicas (la grecorromana y la árabe), provistas de funcionamiento estudiado, prosodia sistematizada y notación particular. Entre las dos hubo en los tiempos medios dos métricas silábico-acentuales (la dialectal arabigoandaluza y la de la poesía en romance). De cada una de estas aspira a tirar cada una de las métricas clásicas: cada cual la suya. Pero no pueden. Las métricas vulgares se abrazan y se defienden. No las enlaza la subordinación, sino la simbiosis. Tienen las mismas dificultades y las mismas soluciones, los mismos métodos y los mismos procedimientos, los mismos méritos y acaso los mismos defectos. Tienen una dimensión común» (1968: 286-287). Esa base común es la que trata de destacar siempre en sus traducciones presididas por un afán de utilizar formas métricas equivalentes en árabe y en español.

5 Oigamos, como ejemplo, el análisis que hace de un fenómeno como el encabalgamiento. Traduzco del francés sus palabras: «El rechazo de la doble organización [sintáctica y métrica] en los versos no es un rechazo inocente. Es posible que deba ser interpretado como la aplicación de un principio más general, que no interesa sólo a la literatura. La prohibición del encabalgamiento se produce en una época en que la burguesía, jugando momentáneamente la carta del poder central contra el feudalismo sobreviviente, pone sobre el tapete una ideología de la razón, que es también una ideología de la racionalización. La victoria de la burguesía, tras la Revolución, se traducirá por la muerte del rey, pero también por la supresión de la complejidad administrativa heredada de una larga tradición. No se trata de decir que la prohibición del encabalgamiento refleje directamente los conflictos del gobernador y del intendente en 
Después de esta enumeración de algunas cuestiones, quien piense que la métrica es un estudio aburrido, de simple recuento, está muy equivocado. La métrica, por el contrario, es punto de partida para la comparación y relación con los más variados aspectos.

Cómo la versología comparada no puede olvidar los factores sociológicos, es lo que afirma Joseph Kvapil (1965) en las conclusiones de su trabajo sobre los intentos de versificación silabotónica en la poesía rumana de la $2 .^{a}$ mitad del s. XIX. Estos ensayos, y los que se dan en la poesía italiana, se explicarían por influencia alemana.

También Samuel Gili Gaya, en su interpretación del versículo de Vicente Aleixandre, establece una relación entre métrica y realidad sociocultural, cuando aproxima esta forma de verso libre a la filosofía existencial. Si el existencialismo, más que sistema filosófico, es «una acuciosa indagación espoleada por la angustia de nuestro vivir contemporáneo», el versículo es también «el vehículo de una actitud indagadora, una exploración sin rumbo, que elude el nombre y la imagen concretos» (1956: 63). De esta manera, el artificio métrico se convierte en «signo histórico-cultural». Se comprenderá que la métrica sea vía de acceso privilegiada en las interpretaciones estilísticas de la poesía (Domínguez Caparrós, 1988: 42-44).

Ilustrada la indudable dimensión comparatista implícita en todo fenómeno métrico y la amplitud de las repercusiones que el uso de los artificios del verso, por lo que suponen de convención en cuya elección hay una dosis de libertad, tienen más allá de lo estrictamente formal, es hora de ir viendo cómo se ha tratado de organizar el estudio comparatista de la métrica.

\section{PROPUESTAS PARA UN PROGRAMA DE MÉTRICA COMPARADA}

Una de las primeras presentaciones generales de métrica que se acogen al rótulo de «métrica comparada» — si no es la primera- es la que hace el formalista ruso Boris Tomachevski, en 1928, en su Teoría de

las provincias. No es quizá imposible sostener que los dos fenómenos no son extraños el uno al otro. La ideología literaria no tiene una existencia independiente. Mantiene relaciones estrechas con las otras formas de ideología» (1974: 23). 
la literatura. Sin que plantee la caracterización explícita de «métrica comparada», trata en primer lugar de la diferencia de prosa y verso, para pasar inmediatamente a describir los tres principales sistemas de versificación (métrico, silábico y tónico), «nacidos en el curso de la historia y difundidos en las literaturas europeas» (1928: 108). El comparatismo métrico de Tomachevski se identifica con las características formales del verso de las principales literaturas europeas. Estas literaturas son, según se desprende de la presencia de ejemplos en su exposición: las literaturas clásicas griega y latina, la alemana, la inglesa, la rusa, la francesa, la italiana, con alguna referenecia a la polaca. Claro que luego se centra en la descripción del verso ruso, para lo que todo lo anterior sirve como contexto general. Pero esta contextualización es necesaria y muy útil, porque de esa manera se entiende una afirmación, que complementa la anteriormente comentada de Jakobson sobre el espíritu de una lengua y determinada forma métrica. Dice Tomachevski:

Es de señalar que muchos metros, considerados rusos nacionales, son típicos metros tónicos isosilábicos, y se encuentran en todas las literaturas que utilizan un sistema de este género (1928: 138).

Se comprueba así cómo la descripción de las formas métricas de una literatura determinada queda mucho mejor trazada desde una perspectiva comparatista.

En el capítulo que Wolfgang Kayser dedica a los «Conceptos fundamentales del verso» (1972: 103-131) hay una evidente perspectiva comparatista en el tratamiento de las cuestiones. Perspectiva que puede ilustrarse con algo de lo que dice en cada uno de los apartados. Así, cuando trata en primer lugar de los «sistemas de verso» enumera los tres que ya conocemos por Tomachevski: silábico, cuantitativo y tónico (germánico). Al mismo tiempo, compara el verso antiguo y el germánico, observando que largas y breves ejercen la misma función que tiempos marcados y no marcados. Cuando habla de las diferentes clases de pies, da la definición clásica antigua y pone un ejemplo alemán e inglés. Cuando trata del verso, lo mismo que cuando habla de estrofa, de los tipos de composición poética o de la rima, hay una perspectiva comparatista. Por ejemplo, cómo la admiración del romanticismo alemán por la poesía española lleva a intentar imitar el octosílabo español, que da lugar a una interpretación trocaica del ritmo del mismo (1972: 110); cómo por la misma razón se intenta aclimatar la asonancia (1972: 127). No nos puede extrañar la atención a lo común 
a varias literaturas en quien hace una proclama como la que hemos reproducido antes a favor de mirar al extranjero cuando se quiere estudiar un verso nacional.

Sigamos nuestro análisis de los contenidos de la métrica comparada. Dentro del programa de poética comparada, Jean-Louis Backès trata de métrica general, y organiza su estudio de la siguiente manera: sistemas de versificación y estructuras lingüísticas, donde, a partir de las grandes literaturas europeas, se deslindan tres grandes sistemas de versificación: silábico, fundado en el número convencional de sílabas; acentual, basado en el cómputo de sílabas tónicas (inglés, alemán y ruso); cuantitativo, que parte de la oposición entre sílabas largas y breves (latín, griego, árabe y persa). Pero sigue matizando el margen de indeterminación del sistema métrico por el material linguiístico, respecto del que se suele establecer una relación. Hay una relación efectivamente, pero hay sobre todo elaboración del material lingüístico. Por eso no extraña el que insista, en un apartado especial, en la multiplicidad de las métricas, como puede ilustrarse en su concepto de métrica francesa:

Podría ser interesante describir el estado actual de la versificación francesa como el resultado provisional de una exploración aún en curso entre las múltiples posibilidades que se ofrecen (1989: 90).

De ahí que continúe con un apartado especial para insistir en la relatividad de las normas y su contaminación de las ideologías, pues la «métrica misma no está pura de toda política» (1989: 91). Y si hay multiplicidad, por supuesto que hay transmisión de las métricas, aspecto que trata al final. Los ejemplos son abundantísimos (haiku, rima de origen árabe...), pues las crisis de los versos se suelen resolver en tentativas de préstamos, y no está de más pensar en una relativa autonomía del dominio métrico.

El trabajo de J.-L. Backès es muy general, pero insiste en los aspectos teóricos que justifican la comparación de la métrica. Se trataría, pues, de una métrica comparada teórica, cuyos principios más generales serían: indeterminación del sistema métrico por el sistema lingüístico, coexistencia de distintas métricas en una misma literatura, relatividad de las normas y posibilidad de intercambio. La insistencia en lo convencional, base del comparatismo, no puede ser más constante y explícita en su presentación de lo que es la métrica general en el marco de la poética comparada. 
El trabajo de Rowena Fowler, «Comparative Metrics and Comparative Literature» (1977) es la más amplia propuesta de un programa de métrica comparada. Merece la pena resumirlo ampliamente. Su punto de arranque, como lo era para Claudio Guillén, es el trabajo de J. Craig LaDrière «The Comparative Method in the Study of Prosody» ${ }^{6}$. Habrá que ir pensando en convertir este trabajo en clásico de la teoría de la métrica comparada. De él toma la idea de partida:

\begin{abstract}
[..] desde que ninguna de las grandes literaturas del mundo tiene un sistema métrico «puro», libre de influencias externas, el método comparativo tiene un importante papel a la hora de mostrar cómo los tipos nacionales o las variaciones del metro han ocurrido y cómo se distinguen de los de otras naciones, y de establecer, si es posible, los rasgos generales de la forma poética que se repiten independientemente de las fronteras nacionales y lingüísticas (Fowler, 1977: 289).
\end{abstract}

A ello añade Rowena Fowler que el estudio comparado de la métrica constituye un acercamiento práctico a la hora de establecer estilos nacionales y personales; un test de la influencia de las fuerzas culturales e históricas en el estilo; una ilustración de la relación entre lenguaje y sistemas métricos.

Sin embargo, a la altura de 1977 , todavía no se había constituido la métrica comparada como una rama de los estudios literarios ${ }^{7}$. La métrica comparada no debe perder de vista su carácter de disciplina literaria. Notemos cómo coincidiendo con propuestas anteriores de Tomachevski, Kayser o Backès, Rowena Fowler afirma que entre lo individual y la métrica universal están las TIPOLOGÍAS, y este parece ser un terreno útil como punto de partida: comparación en una tipología o entre tipologías.

${ }^{6}$ Leído en el ICLA de 1959, y publicado en Werner P. Friederich, ed. Comparative Literature: Proceedings of the International Comparative Literature Association, Chapel Hill, N. C., 1959, I, 160-175.

7 Las razones, según R. Fowler, son: 1.- Los traductores, muchas veces, lo primero que hacen es tirar por la borda la forma métrica del original que traducen; 2.- cuando incluso el hablante nativo no suele analizar bien los versos, es mucho más difícil aún que alguien aprecie las sutilezas métricas en más de una lengua; 3.- la influencia de la lingüística, que tiende a enfatizar la dependencia que la métrica tiene respecto de su lengua, y a reducir la métrica a una parte de la fonología. El móvil de la traducción precisamente está en la base de la amplia comparación del verso español y el verso europeo propuesta por $O$. Bĕlič en su reciente obra (2000). El trabajo del profesor Bélic constituye una referencia imprescindible para la métrica comparada española. El hecho de traducir y reflexionar sobre la traducción en verso explican la vertiente comparatista que da a sus dos recientes trabajos Esteban Torre $(1999,2000)$. 
Insisto en que la asimilación entre métrica comparada y tipologías métricas parece que es el terreno más propia e indiscutiblemente aproximado a lo que es un estudio comparativo del verso. ¿Qué tipologías cita Rowena Fowler? Las de John Lotz, Jiri Levy y Morris Halle ${ }^{8}$.

La tipología de Levy, a la que Fowler se refiere únicamente para decir que ilustra cómo en los grandes tipos pueden distinguirse subtipos (Levy estudia los sistemas silábico-acentuales), puede ser sintetizada por nosotros en el siguiente cuadro:

\begin{tabular}{lcc}
\hline \multicolumn{1}{c}{ Acentual } & Silábico-acentual & Silábico \\
\hline A. Inglés & & \\
A. Escandinavo & Alemán & \\
A. Alto Alemán & Inglés Ruso Checo & Polaco Español Francés \\
\hline
\end{tabular}

El cuadro, recogido en la conclusión de su trabajo, va precedido de las siguientes palabras, que traducimos del inglés:

La divisón aceptada de las versificaciones europeas en tres grupos (acentual, silábico, silábico-acentual) solamente da una muy tosca idea de sus verdaderas relaciones. En la poesía de las principales literaturas europeas, operan dos principios básicos: el acento y el número de sílabas. Las diferencias en la función de los dos principios en las lenguas particulares son graduales, dando como resultado una serie de versificaciones, cada una un poco diferente de las otras (Levy, 1961: 188).

Incluso pensando en la métrica española hay lugar para discutir hasta qué punto esa graduación no se da también en el interior de cada una de las versificaciones ${ }^{9}$.

Para terminar con la amplia referencia al trabajo de Rowena Fowler, espigo algunas de las interesantes observaciones allí contenidas y que insisten en el relativismo de las tipologías, la no dependencia mecánica de las normas métricas respecto del sistema lingüístico, o la insistencia en el carácter convencional de los mecanismos de la versificación.

${ }^{8}$ La del primero establece una división en dos sistemas: simple (sólo se funda en el número de sílabas) y complejo (basado en el número de sílabas + un rasgo prosódico, que puede ser: duración (cuantitativo); acento (silábico-acentual); tono (pitch) (tónico).

9 Véase, al respecto, la presentación que hacemos de los sistemas de versificación española, que matiza, sin duda, la caracterización de la métrica castellana como exclusivamente silábica (Domínguez Caparrós, 2000). 
Sobre esta base el comparatismo métrico tiene un campo amplísimo de investigación. Por ejemplo: 1.- las literaturas que más se relacionan, como la francesa y la inglesa, pueden pertenecer a sistemas muy distintos de versificación; 2.- se ha establecido una semejanza entre el antiguo verso «tumbling» [retozar, caer] inglés con el verso de arte mayor castellano, con lo que queda ilustrado que el verso español puede estar más cerca del inglés que del francés, su vecino lingüístico. Aunque las lenguas con finales vocálicos favorecen la rima, el italiano la tiene y el japonés no. El silabismo del polaco, donde las palabras tienen acento fijo en la penúltima sílaba, sólo se entiende a partir de las influencias francesa e italiana y sus estrechos vínculos con la Iglesia Católica.

Se entiende que en el plan de métrica comparada propuesto por $\mathrm{R}$. Fowler entren tareas tan variadas como: comparar los metros más corrientes en una literatura nacional y relacionarlos con su lengua; un acercamiento a través de la poética, por ejemplo, la relación entre metro y género, que cambia de época y país; estudiar un mismo rasgo (por ejemplo, el encabalgamiento) en distintas literaturas; o una comparación intralingüística. Comparación que puede partir de que en una misma lengua puede haber distintos sistemas métricos; o de que una lengua muy extendida es sometida a influencias muy diversas ${ }^{10}$; o de cómo un mismo sistema métrico puede cambiar las formas según el lugar y el tiempo: comparación diacrónica interna; o de cómo la métrica se relaciona con la estética, y un estilo métrico (de un autor) se entiende mejor comparándolo con el de otro autor.

Tampoco hay que olvidar la comparación con puntos de vista no literarios: por ej., la relación entre sociedades democráticas y preferencia por formas más dinámicas, más sueltas; o la comparación entre naciones con la misma lengua: ¿existen «dialectos» métricos?; en toda literatura «nueva» la métrica forzosamente es comparada; un pueblo colonizador puede recibir la influencia del colonizado más culto (latín adopta el sistema métrico griego); la asimilación de formas extranjeras enseña también cómo interactúan y se modifican: por ejemplo, el soneto italiano se modifica en inglés; el haiku se naturaliza en distintas literaturas ${ }^{11}$.

10 Benjamin Hrushovski analiza cómo la métrica yidish se hace acentual en los países germánicos, silábico-acentual en la Europa oriental, y libre en países de influencia americana.

11 No me resisto a traducir el último párrafo de este interesantísimo trabajo: «Las repercusiones cuando se juntan las lenguas o las literaturas son infinitas, y el campo es muy ancho para el metricista comparatista. Lo mismo que la lengua y la literatura 
Pero no sería justo terminar esta presentación teórica de la métrica comparada sin hablar de la que sin duda es la mejor descripción comparada de los sistemas de versificación de las principales literaturas europeas. Me estoy refiriendo al libro de Mikhail Leonovich Gasparov, Historia de la versificación europea, publicado en ruso en 1989, traducido al italiano en 1993 (Bologna, Il Mulino) y al inglés en 1996 (Oxford, Clarendon Press). Del prefacio a su obra destacamos, por un lado, la importancia que se asigna a la métrica en la historia de la poesía. Dice, por ejemplo, M. L. Gasparov:

La historia de la forma del verso es uno de los componentes más importantes de la historia de la poesía. [...] Cuanto mejor conocemos la historia de la versificación, más profundamente entendemos el significado de cada poema que leemos [Traduzco de la edición inglesa, 1996: VI].

Como objetivo de su libro se plantea el reunir los primeros resultados obtenidos por una disciplina joven: la métrica comparada. Esta disciplina, de la que trata en el capítulo de la introducción, se identifica con la métrica histórica comparada que trata de la historia del verso y que surge en el siglo XIX con el afán de encontrar la versificación original primitiva. Los alemanes fueron pioneros, pero son más aprovechables las tesis de A. Meillet acerca de una común base silábica en las primitivas formas del verso indoeuropeo (Les origines indo-européenes des mètres grecs, 1923), apoyadas después por los estudios de Jakobson sobre el verso eslavo, por ejemplo. Parece, pues, que Gasparov asocia métrica comparada e historia de la versificación tal como se plantea en el siglo XIX, y parece considerar a Antoine Meillet como su fundador. Y después de enumerar los rasgos hipotéticos del verso indoeuropeo (por ejemplo: silábico, con una forma corta -de 8 sílabas - y otra larga dividida en hemistiquios — de 10 a 12 sílabas-, sin regularidad en el elemento tónico -el acento-, y con ciertas reglas de cantidad en las cinco últimas sílabas), termina con un párrafo que sirve perfectamente de resumen de su trabajo:

Nuestra tarea será trazar el desarrollo de esta común herencia indoeuropea en las distintas lenguas y grupos de lenguas. Primero tendríamos que tratar

confluyen en el metro, la lingüística comparada y la literatura comparada confluyen en la métrica comparada, que desde ese momento es capaz de dar una sólida fundamentación linguística al estudio de la poesía sin olvidar la parte que juegan en su proceder la tradición cultural y la imaginación literaria» (1977: 299). 
de las lenguas en las que el sistema silábico original o era mantenido o evolucionó a un sistema tónico (las lenguas eslavas y germánicas); después, de las lenguas en las que el sistema silábico original evolucionó a un metro cuantitativo (griego y latín); después, del resurgimiento del verso silábico a partir del metro cuantitativo en el griego y latín medievales, y en las lenguas románicas que se desarrollaron a partir del último; y finalmente tendríamos que tratar de la forma en que el verso silabotónico germánico surgió en la conjunción del verso silábico románico y el verso tónico germánico, y gradualmente se extendió casi a toda Europa (1996: 9-10).

Es sorprendente cómo puede llegar a una síntesis tan clara, tan bien fundada en una documentación muy copiosa, y que proporciona el mejor contexto europeo para la comprensión de los distintos sistemas de versificación. El estudioso de la métrica española puede hacer la comprobación en las atinadas indicaciones para la inserción del verso español en su contexto europeo. La diversidad de la forma del mismo y su parecido con otros sistemas quedan perfectamente demostrados, y esto aleja la tentación de la explicación del sistema del verso español en las manifestaciones de su larga y rica historia.

\section{Referencias bibliográficas}

ARISTóteles (1974). Poética. Edición trilingüe por Valentín García Yebra. Madrid: Gredos.

BACKÈs, J.-L. (1974). «La place et le rôle de la métrique dans la théorie de la littérature». Littérature (París) 14, 19-35.

- (1989). «Poétique comparée». En Précis de littérature comparée, Brunel, P. et Chevrel, Y. (eds.), 85-103. Paris: PUF.

BĚLIČ, O. (2000). Verso español y verso europeo. Introducción a la teoría del verso español en el contexto europeo. En colaboración con Josef Hrabák. Santafé de Bogotá: Instituto Caro y Cuervo.

Brunel, P.; Pichois, C.; Rousseau, A.-M. (1983). Qu'est-ce que la littérature comparée? Paris: Armand Colin.

Domínguez CAPARRós, J. (1988). Métrica y poética. Bases para la fundamentación de la métrica en la moderna teoría literaria. Madrid: UNED.

- (2000). Métrica española, segunda edición revisada. Madrid: Síntesis.

ETIEMBLE (1974). Ensayos de literatura (verdaderamente) general. [Versión española de Roberto Yahni.] Madrid: Taurus, 1977.

FOWLER, R. (1977). «Comparative metrics and comparative literature». Comparative Literature 29, 289-299.

GÁLDI, L. (1964). Esquisse d'une histoire de la versification roumaine. Budapest: Tankönyvkiadó. 
GARCía GómEZ, E. (1968). «Introducción a una métrica de Ben Quzman». AlAndalus 33, 241-290.

GASPAROV, M. L. (1996). A history of european versification. [Translated by G. S. Smith and Marina Tarlinskaja.] Oxford: Clarendon Press.

GiLI GAYA, S. (1956). El ritmo en la poesía contemporánea. Barcelona: Universidad de Barcelona.

GUILLÉN, C. (1985). Entre lo uno y lo diverso. Introducción a la literatura comparada. Barcelona: Crítica.

JAKOBSON, R. (1923). «Principes de versification». En Questions de poétique, 1973, 40-55. Paris: Seuil.

KAYSER, W. (1972). Interpretación y análisis de la obra literaria. [Versión española de María D. Mouton y V. García Yebra.] 4. ${ }^{\text {a }}$ edición revisada, reimpresión. Madrid: Gredos.

KVAPIL, J. (1965). «Systèmes de versification et les contrecoups de la civilisation dans les langues romanes». En Omagiu lui Alexandru Rosetti, 461466. Bucuresti: Editura Academiei Republicii Socialista Romania.

LEVY, J. (1961). «A contribution to the typology of accentual-syllabic versifications». En Poetics, Poetyka, International Conference of Work-inProgress devoted to Problems of Poetics (Warsaw, August 18-27, 1960, 177-188. 'S-Gravenhage: Mouton.

LoTZ, J. (1974). «Metrics». En Current Trends in Linguistics, Thomas A. Sebeok (ed.), 963-968. The Hague: Mouton.

MARINO, A. (1988). Comparatisme et théorie de la littérature. Paris: PUF.

MeletinsKy, E. (1989). «Sociétés, cultures et fait littérarire». [Revu par Jean Bessière.] En VV. AA., Théorie littéraire, 13-29. Paris: PUF.

SCHMELING, M. (1984). «Introducción: literatura general y comparada. Aspectos de una metodología comparatista». En VV.AA., Teoría y praxis de la literatura comparada, 5-38. [Traducción de Ignacio Torres Corredor.] Barcelona: Editorial Alfa.

ToMACHEVski, B. (1928). Teoría de la literatura. [Traducción: Marcial Suárez.] Madrid: Akal, 1982.

TORRE, E. (1999). El ritmo del verso. Murcia: Universidad.

- (2000). Métrica española comparada. Sevilla: Universidad.

Wellek, R.; WarRen, A. (1969). Teoría literaria. [Versión española de José M. ${ }^{a}$ Gimeno.] Cuarta edición, reimpresión. Madrid: Gredos. 